\title{
Research on the Legal System of International Tax Collection and Management under the E-commerce Environment
}

\author{
Shuting Yang \\ Harbin Engineering University, 150001
}

Keywords: e-commerce, international tax collection and management, legal system

\begin{abstract}
With the rapid development of information technology, e-commerce as a brand-new trade model is well known and has become an important trading mode in the current trade market in China. Its trading technology and consumption concept penetrate into every aspect of society rapidly, producing a huge impact on both China's economic growth and international competitiveness. At the same time, all countries in the world recognize the importance of e-commerce. They start to formulate e-commerce development plans in line with national characteristics, and begin to gradually focus on the enormous opportunities brought by e-commerce. In this context, international tax collection and management issues involved in the operation of e-commerce have become increasingly prominent, which poses new challenges to the existing tax laws in China. In the process of tax collection, under the environment of e-commerce, important information such as tax payers, tax objects, tax links, location confirmation and so on are faced with unpredictable problems. Since traditional taxation methods have obviously been unable to meet the requirements of international e-commerce tax collection and management, tax can not be effectively collected, but also produced a new type of international tax avoidance. Facing the above series of problems, this paper will analyze and study the legal system of international tax collection and management under the environment of e-commerce.
\end{abstract}

\section{Introduction}

E-commerce is an electronic business model based on information network technology, which takes virtual electronic space as the carrier. Since 1990s, it has shown great vitality and has developed rapidly in recent years. In the foreseeable future, e-commerce will inevitably become a worldwide business model, whose development has brought about new changes to the society and will exert strong influence on the economic and social development in the future world. For example, the enormous impact of e-commerce on American retail industry has pushed itself to be included in the national strategic development planning, which is why that the tax issues related to e-commerce have become the focus of attention among various international countries. Meanwhile, e-commerce has brought great impact to the tax revenue of all countries. Because e-commerce is based on network construction, it has the borderless and global characteristics, so the legal system of tax collection must be reformed and innovated based on such characteristics.

\section{Views on International Tax Collection and Management under the E-commerce Environment}

There are two different opinions on whether the international e-commerce tax should be levied. Experts and scholars against levying international e-commerce tax believe that e-commerce taxation violates the principle of market freedom, while those in favor hold that e-commerce will pose a certain threat to the existing tax base and may lead to new tax loopholes, so it is necessary to adopt new ways to deal with this challenge, otherwise a large amount of government revenue would be lost on the Internet. Some think that under the environment of information society, government functions often determine the inevitability of taxation in a series of e-commerce activities. Under this background, whether public goods can be effectively provided is still a serious problem, which also shows that the management, maintenance and construction of e-commerce market still need 
governments' appropriate intervention. In addition, some experts have linked the collection of e-commerce tax with the protection of information resources. They believe that government should levy a certain e-commerce tax from the perspective of protecting information resources, protecting the development of information resources and utilizing public networks and goods. Therefore, there are great differences on whether to levy e-commerce tax in international or domestic areas. At present, more scholars support to levy e-commerce tax, which will have a certain impact on the levy of e-commerce tax in China.

Because e-commerce tax has a lot of uniqueness, so in the process of specific collection, whether the country should set up corresponding tax type according to the actual situation of tax collection is also a hot issue which has aroused the attention and intense discussion of academic circles. Some experts and scholars believe that before formulate relevant policies on e-commerce taxation, it is necessary to firstly determine the basis of our country's current tax system, and make necessary improvements and modifications in order to make it more adapt to the characteristics of e-commerce mode and development law, effectively reduce the hidden risks in the fiscal levy, and make the current tax collection and management suffer less impact. While some support that e-commerce should belong to the field of commodity economy. Although the way of transaction differs, content is not too different from the traditional trade. Some professionals suggest that China can follow the Canadian "Bit Tax" concept. At the same time, some experts point out that with the transformation and development of commercial society, e-commerce taxes can be collected by setting up new tax sources and transaction taxes. There are too many voices on whether an e-commerce tax should be levied. Experts and scholars from all sides insist on their opinions. Professionals who want to collect this tax mainly consider it from the perspective of maintaining the current transaction order and relevant laws. Those who do not advocate levying this tax also hope to find other ways to deal with the problem so that the contradiction of whether e-commerce tax should be levied or not can be solved properly. There are also different views on the issue of international tax collection and management of e-commerce. For example, e-commerce taxes can protect the financial needs of our country. If the collection departments fail to formulate corresponding collection methods in a timely manner and there is a lack of corresponding laws and regulations to restrict various acts of electronic commerce, it will lead to the vacuum or absence of tax collection and management system, so some advocate the collection of international tax on electronic commerce. Some experts believe that e-commerce taxation can better reflect the fair value. All things that are regarded as the same by law should be treated in accordance with the law.

If the law treats differently, it will lead to the loss of the credibility of law, and it will become an unjust law and regulation. Professionals have made a deep research and discussion on whether or not to collect international tax on e-commerce from many angles, pointing out the heading way for tax system and legislation of electronic commerce in our country. At the same time, it is proposed that only by mitigating and eliminating the impact of international electronic commerce tax on our tax revenue, can we improve the relevant legal system of our country.

At present, the impact of international tax collection and management system of e-commerce on the traditional tax system is mainly reflected in the basic principles. The basic principles of tax law in our country mainly imply or are stipulated in the legal system of taxation. Research on legislation, law-abiding and tax law has definite guidance and use value, which belongs to the fundamental principle of tax laws and regulations in our country. The principle of fairness in taxation mainly refers to the fact that when the state collects taxes, it requires each individual to bear the appropriate amount of money in accordance with their operation and economic situation, and to ensure the balance of each individual tax payer. However, since e-commerce transaction has the open characteristic, the main body of e-commerce transaction may bear different tax burden in the same transaction nature, which will cause the existence of unfair tax burden in the main body. Another major problem is that it is difficult to define a permanent establishment. On the basis of the principle of equity, profits of enterprises in the territory of both contracting states are subject to local taxation rights, that is, the enterprises of one of the contracting states have a physical presence in their national territory, which is also based on the objective existence of a permanent 
establishment. The confirmation of permanent establishment relates to those, such as according to which country's standards to exercise the national and transnational tax jurisdiction, how to divide interests between the contracting parties, as well as how to coordinate tax disputes between our country and other developed countries. Although the server on which the web site is located can be used as a physical device, in international e-commerce transactions, the country in which the server is located is not owned by the seller, which makes it difficult for the permanent establishment to identify and classify. Meanwhile, the tax collection of e-commerce also becomes more and more complicated with the progress of computer networks. China's current legal system of tax collection and management is based on the supervision of buyers and sellers, while some European and American countries have established a monitoring payment system, in which e-commerce is deducted by banks. It is difficult to determine the jurisdiction of e-commerce, and especially the trade behavior in the form of electronic commerce aggravates this contradiction. Cyberspace is not traceable, and it is difficult to determine the source of revenue, so the issue of regional jurisdiction is more prominent.

\section{Research on the Legislation and Policy of International Tax Collection and Management for E-commerce in Different Countries}

The rapid development of network economy in the United States has benefited greatly from the consistent tax-free policy towards the network economy, in which no additional tax will be levied on e-commerce, and network is divided into tax-free zones. It ensures that the neutral principle of taxation and network education will not be affected because of normal tax behavior. In addition, when other countries use the existing tax principles, they should try their best to achieve unity, while unclear international tax revenue needs to be supplemented. In order to ensure the rapid development of e-commerce, no value-added tax or consumption tax will be levied on online transactions, and the tax jurisdiction of residents will be strengthened. At present, the United States is focusing on the related technical issues which are encountered when the traditional resident tax jurisdiction is applied in e-commerce. The United States is the world's largest exporter of e-commerce, and the use of e-commerce conservative taxation to expand the interests of international taxation is the fundamental principle of legislation.

In view of this problem, the attitude of developing countries shows many contradictions. First of all, developing countries need to worry that once tariffs on online transactions are lifted, goods from developed countries will enter through the Internet without any hindrance, so that their markets will be occupied by a large number of developed countries' commodities, which will have a negative impact on the development of their domestic counterparts. That is why many developing countries have raised objections to the World Trade Organization's Permanent Extension of Taxation on Electronic Commerce. However, developing countries also need to worry that a tax would hinder their e-commerce development. The vigorous development of e-commerce has obviously attracted the attention and recognition of countries all over the world. Any country does not want e-commerce to hinder and affect its economic growth. It is precisely because of this contradiction that developing countries can not make a clear decision on whether to levy e-commerce tax internationally. When developing countries legislate on this tax, they need to take into account both the protection of their own tax interests and the confrontation of interests between them and developed countries. Meanwhile, they need to consider that importance of e-commerce in promoting their own economic development can not be hindered. Therefore, up to now, most developing countries do not have relevant tax laws and regulations to restrict e-commerce transactions. The main reasons include that the division of interests involved in transnational business activities has not been unified internationally. Therefore, many developing countries hold a wait-and-see attitude, but there is still a great deal of caution about the United States, which implies that the tax base of developing countries will shrink dramatically and financial resources will drain away. As a developing country, e-commerce in China started relatively late, and there are still some technical and security problems on network. Therefore, proceeding from the actual situation, in a considerable period of time, China will still be a net exporter of e-commerce, so in the distribution 
of tax, we should always adhere to the tax jurisdiction, and take it as the basic starting point of our policies.

\section{Conclusion}

To sum up, under the environment of e-commerce, research on the legal system of international tax collection and management is quite hot. Different opinions have been put forward from various fields on whether and how to levy taxes. When facing this problem, China should adhere to the basic principles of taxation, combine new situation with new development, and explore in practice to constantly seek better programs as the relevant tax policy and legislative basis, and ensure the basic interests of China on the basis of vigorous development of e-commerce.

\section{References}

[1] Liu Xiaofan. Research on the Administration of China's Cross-border E-commerce Import VAT [D]. China Academy of Financial Sciences, 2017.

[2] Xu Jianan. Adjustment and Improvement of China's Tax System under the E-commerce Environment [D]. Daqing Petroleum Institute, 2007.

[3] Dai Lu. Research on the Legal Issues of Tax Collection and Management under the E-commerce Environment [D]. China University of Political Science and Law, 2007.

[4] Luo Jiali. Disscussion on the Tax Law Problems under the E-commerce Environment in China [D]. Xiangtan University, 2016.

[5] Xu Jinghuan. Research on the International Tax Law under the E-commerce Environment [D]. China University of Political Science and Law, 2010. 